\title{
(RE)FRAMING SPATIALITY AS A SOCIO-CULTURAL PARADIGM: EXAMINING THE IRANIAN HOUSING CULTURE AND PROCESSES
}

\author{
Lakshmi RAJENDRAN (1D) 1, ${ }^{*}$, Fariba MOLKI ${ }^{2}$, Sara MAHDIZADEH (1D) ${ }^{3}$, Asma MEHAN (1) 4 \\ ${ }^{1}$ School of Engineering and Built Environment, Anglia Ruskin University, Chelmsford, UK \\ ${ }^{2}$ Department of Technology and Arts, Georgian College, Canada \\ ${ }^{3}$ Department of Architecture and Urbanism, Ferdowsi University of Mashhad, Mashhad, Iran \\ ${ }_{4}^{4}$ Institute of Cultural Anthropology and Development Sociology (CADS), Leiden University, Leiden, Netherlands
}

Received 15 December 2020; accepted 22 April 2021

\begin{abstract}
With rapid changes in urban living today, peoples' behavioural patterns and spatial practices undergo a constant process of adaptation and negotiation. Using "house" as a laboratory and everyday life and spatial relations of residents as a framework of analysis, the paper examines the spatial planning concepts in traditional and contemporary Iranian architecture and the associated socio-cultural practices. Discussions are drawn upon from a pilot study conducted in the city of Kerman, to investigate ways in which contemporary housing solutions can better cater to the continually changing socio-cultural lifestyles of residents. Data collection for the study involved a series of participatory workshops and employed creative visual research methods, participant observation and semi structured interviews to examine the interlacing of everyday socio-spatial relations and changing perception of identity, belonging, socio-cultural and religious values and conflict. The inferences from the study showcases the emerging social and cultural needs and practices of people manifested through the complex relationship between residents, the places in which they live, and its spatial planning and organisation. For a better understanding of this complex relationship, the paper argues the need for resituating spatiality as a socio-cultural paradigm.
\end{abstract}

Keywords: spatial, socio-cultural, housing, planning, architecture, Iran.

\section{Introduction: people and spatialities}

Our existence is always in relation with something in the physical world, a spatial relation that is fundamental to all our experiences. The inherent interrelationship between people, place and activities make spatiality, an essential constituent of understanding peoples' experience and perception. Often the spatiality of our existence is so obvious that it becomes invisible in our everyday living. Political geographer and urban theorist Soja explain that, as "spatiality tends to be peripheralized into the background as reflection, container, stage, environment, or external constraint of human behaviour and social action" (Soja, 1996, p. 71). Environmental psychologists argue that, as physical, cognitive structures are more complex than social and personal cognitive structures, and being subtle they tend to be remote from the awareness of the individual because physical settings are "backdrops" against which events occur (Proshansky et al., 1970a). Philosophers laments that "nothing we do is unplaced and how could we fail to recognize this primal fact" (Casey, 1998, p. 9). Malpas goes further stating "space must be the most fundamental concept in almost every domain" (Malpas, 2012, p. 227) declaring the importance of spatiality for studying any phenomenon.

Within the domain of architecture and, also philosophy, the essence of people and spatial relations lie in the very basis of existential meaning, produced by one's interaction with the physical world. Architectural theorist, Norberg-Schulz described how "these meanings and structures are reflections of man's understanding of the natural environment and his existential situation in general" (Norberg-Schulz, 1980, p. 50).

Physical settings, simple or complex, evoke complex human responses in the form of feelings, attitudes, values, expectancies, and desires and it is in this sense as well as in their known physical properties that their relationship to human experience and behaviour must be understood (Proshansky et al., 1970b, p. 28). Regardless of any strong characteristics or qualities, spatial relationships enable human responses constituting peoples' everyday life both

*Corresponding author. E-mails: lakshmi.rajendran@aru.ac.uk; lakshmirajendran2015@gmail.com 
consciously and unconsciously. Social psychologist Altman explains that there are three general ways to relate the physical environment to social relationships and psychological processes:

(1) as an independent variable in which aspects of the environment affect or cause variations in interpersonal processes;

(2) as an aspect of behaviour, for example, use of space, personal spacing, territorial behaviour, use of the environment to regulate privacy, possession and display of prized objects, to decorate or to personalize places and so on; and

(3) as a context or setting within which psychological processes, relationships and behaviours are embedded (Altman, 1992, p. 269).

The third aspect Altman considers superior, reflects the physical environment becoming "part of the definition and meaning of the phenomenon" (Altman, 1992, p. 272), occurring where place and people interact, and develop a transactional relationship. The quality of such relationships remains crucial, as Gifford explains: "every aspect of human existences occurs in one environment or another, and the transactions with and within them has important consequences both for people and their natural and built worlds" (Gifford, 2014, p. 545). It is through such transactions that societies develop a sense of identity.

With rapid changes in urban living today, peoples' behavioural patterns and spatial practices undergo a constant process of adaptation and negotiation. The changing socio-cultural relationships, values and processes are, complex, challenging and contested concepts for investigation. This paper strives to generate an understanding of socio-cultural processes through the lens of spatial relations within houses which offers the matrix for developing, restructuring, defining peoples' perceptions and everyday life. Discussions are drawn upon from a pilot casestudy conducted in the city of Kerman, which aims to investigate ways in which contemporary housing solutions can better cater to the continually changing lifestyles of residents, whilst retaining various cultural and symbolic connotations that are embedded in various spaces in a house, in the city of Kerman. Data collection for the study involved a series of participatory and narrative workshops with participants, and employed creative visual research methods, and semi structured interviews to examine the interlacing of everyday socio-spatial relations and changing perception of identity, belonging, socio-cultural and religious values and conflict. Based on the inferences, the paper proposes a conceptual multi-dimensional framework model grounded in spatial relations and practices, offering an interesting lens for examining the socio-cultural processes and urban transformations in cities.

\section{House, home, dwelling - spatial relations and meanings}

House, home and dwelling are interlinked concepts which present a rich domain to unravel and examine the complex, experiential spatial relationship of the resident. The meanings of these interlinked concepts are diverse in relation to individual and societal values, beliefs and practices. The different spaces in-house, Johnson explains, "will be organized around and will express the worldview, or mentality of, the society that produces it, and will express that view, but this worldview, in turn, has to be understood in terms of that society" (Johnson, 1993, pp. 32-33). A seminal work that looks at the house as an intimate and profound object is "The Poetics of Space" by Bachelard. Bachelard explains how the house offers intimate experiences that are strongly fixed in the human mind. He argues that the experiences of one's house are one of the "greatest powers of integration for the thoughts, memories and dreams of mankind" (Bachelard, 2014, p. 6). According to Bachelard, the house is a container for daydreams, and in order to examine and analyse "being" more deeply, it is crucial to understand the experiential plane evoked by different places in the house which are identified by one's solitude. Through his philosophical analysis of the houseperson relationship, Bachelard coined the term "topoanalysis", a "systematic psychological study of the sites of our intimate lives" (Bachelard, 2014, p. 46) and explained such an analysis could be instrumental in psychoanalysis.

Miller simplified the definition of home stating that in traditional anthropological debates the meaning of home refers to a specific location that is bounded spatially with four walls, windows and doors (Miller, 2001, p. 2). Contrary to this functional description, Douglas considers it an early form of social organisation, as a home is a place where households organise themselves over time by practising the planning of resources and by developing household rituals (Miller, 2001, p. 50). A multi-dimensional and multi-layered approach to home by Cuthbert sees it as "the universal physical medium of expression for humans". He suggests that as a basic meaning, home can be a place for several primary or personal functions, such as washing cooking, eating etc. However, there is something more than this that might be related to history or spiritual aspects. Norberg-Schulz signifies the profound relation with home as a touchstone for a meaningful place stating that "when the environment is meaningful man feels "at home"' (Cuthberted, 2003, p. 23).

Marcus argues that a home meets many needs: "a place of self-expression, a vessel of memories, a refuge from the outside world, a cocoon where we can feel nurtured and let down our guard" (Marcus, 2006, p. 4). Home offers a fundamental platform for nurturing our personal, social and cognitive skills to function in the society as "homes are places where people grow up and know exactly how to walk on a specific part of the ground, or to be under a specific sky" (Marcus, 2006, p. 23). Marcus (2006) says that "home can be a room inside a house, a house within a neighbourhood, a neighbourhood within a city, and a city within a nation. At each level the meaning of home gains in intensity and depth from the dialectical interaction between the two poles of experience - the place and its context at a larger scale" (Marcus, 2006, p. 191). She further adds that "home is a place of security within an 
insecure world, a place of certainty within doubt, a familiar place in a strange world, a sacred place in a profane world. It is a place of autonomy and power in an increasingly heteronomous world where others make the rules" (Marcus, 2006, p. 205).

Birdwell-Pheasant and Lawrence-Züniga explain house as a place that "belongs to a particular group" (Birdwell-Pheasant \& Lawrence-Züniga, 1999, p. 51). They believe that although houses involve areas for making food, eating, sleeping, sitting, storing etc., tensions often arise between meaning and praxis (Birdwell-Pheasant \& Lawrence-Züniga, 1999, p. 51). The negotiating processes of these conflicts and tensions again get manifested in the form of spatial tactics and practices which are adapted and appropriated over different time in diverse cultures.

In phenomenological traditions, the notion of dwelling is grounded in existential meaning. Heidegger considers "building" and "dwelling" to be a single phenomenon (Lane, 2006, p. 50). Heidegger defines "dwelling" as "the way in which you are, and I am, the way in which we humans are in the earth" and "the world is the house where the mortal dwells" (Heidegger, 1971/2001, p. 10). The concept of deep-rootedness and being emplaced characterises dwelling in phenomenology " dwelling means to remain in a place and be situated in a certain relationship with existence", referring to a relationship that is characterized by nurturing, enabling the world as it is (Heidegger, 1971/2001, pp. 150-151). Dwelling also reflects distinct characteristics as "A dwelling has to be "protective", an office "practical", a ball-room "festive" and a church "solemn" (Norberg-Schulz, 1979, p. 14). Norberg-Schulz "used the word "dwelling" to indicate the total man-place relationship" (Norberg-Schulz, 1979, p. 22). Schulz states that although orientation is one of the significant spatial relationships, dwelling relates more to identity and that it is not possible to position oneself without valid identification (Norberg-Schulz, 1979, pp. 20-21).

As discussed above the interlinked concepts of home, house and dwelling showcase how spatial relations and structures are linked at different levels of meanings, perception and experience of people. However, the spatial structures in a house and their associated meaning and relations are in themselves shaped by their respective socio-cultural milieu in which they are founded).

\section{Concept of "house" in Iranian culture}

Language and culture are evolving concepts. Some words, and aspects of culture, change with time. These gradual changes significantly reflect peoples' changing perceptions of various aspects of living. How people adapt to their place of living and how they describe it, is largely defined by their social and cultural choices and preferences. This notion is aptly demonstrated when understanding the concept of "house". In Persian culture, the meaning of house (khane) is "a place for dwelling" (Dehkhoda, 1940, p. 321). However, the Dehkhoda glossary notes that in Persian, there are more than fifty words that include the word "house". In these combined words, "house" is used as a suffix. These words may be categorised into five groups: occupation, objects, activities, characteristics and space.

Occupation: When the word "house" is added as a suffix to some words, it indicates the occupation of the person occupying the house. For example, "akas-khane" in Persian, if translated literally, means "the photographer's house", but it is used to refer to a "photo shop". This is also applicable to words like cook and so on.

Objects: The word "house" can also be added as a suffix to objects such as tea, pit, medicine or fund - indicating the social function or role of a building. A medicine house, for example, is a pharmacy.

Activities: The word "house" can be added as a suffix to verbs that relate to an activity, such as observing or reading; thus, a reading house in Persian is a library in English.

Characteristics: The word "house" when added as a suffix to specific words such as cold and warm describes their characteristics. A cold house means a cold room.

Spatial: When the word "house" is added as a suffix to words describing certain spaces, it refers to the spatial conditions and location of space. Referring to a "dome house" articulates a space that has a dome above it. Putting these words together offer some glimpses of sociocultural and material aspects in everyday life in Iran.

Combining these words with "house" creates another image of space. On the other hand, the way, the word "house" is used also provides a glimpse of how everyday life and society are connected. When a function/role or a type of service becomes permanent and essential or a relevant part of society, people like to allocate it a specific place: a house. "House" is considered to represent a place that people settle in, it often represents a social and/or personal part of human life. In the past few decades, Iranian society has faced several cultural and social changes (explained in the later section) and, accordingly, the meaning of house has been affected, and now different terms are used to describe a "house". According to architecture historian Pirniya, Iranians have started to use the word "room" (otagh) instead of the word "house" (khane). The word "house", which was added to different words in the past, as mentioned before, is rarely used now. Instead, they have been replaced by some new names that not only relate more closely to western names for those spaces, but also play roles that are more similar to their western counterparts.

\section{Spatial relationships of traditional Iranian courtyard houses before the 20th century}

In traditional Iranian society, houses were designed in a way that separated the "inside and private" from the "public and outside". Individual houses were clustered into a parish, which was a complex of compact houses that were built back to back, with each house having its own courtyard, which evolved into a distinct traditional housing typology in Iran. Before stepping into the 20th century, in the traditional atmosphere of Iran, the inward-looking 
houses located in the historical cities such as Kashan, Isfahan, Shiraz, and Kerman, generally consisted of two main parts: Andaruni (interior) the private quarters of dwellings for females. Moreover, Biruni (exterior), the public reception for male guests is situated close to the main entrance (Refer Figures 1-4).

Generally, spatial relationships between the aforementioned private and public domains and access design of some Iranian houses contained a particular rule. The main entrance is followed by Hashti (vestibule). The function of Hashtimay be a temporary waiting place (with niches) that provide access to the public and private areas through the corridor. The staircase from Hashtiwould lead to the roof. Its plan could be "octagonal, square, or rectangular shapes" (Memarian, 1998, p. 100). After passing through the Hashti, there was a courtyard or garden which could be square or rectangular. According to Rapoport (2007), there are some criteria attributed to courtyard houses: "the nature of the privacy", providing settings for the occurrence of specific activities; as a means for accessing other spaces; the ability to allow a "more efficient" use of space, and finally having climatic comfort and efficiency.

The courtyard being linked to semi-open space is known as Ivan. In the courtyard-houses the position of Ivan could differ in three ways; in front of all the rooms, among the rooms, or one side of the rooms (Memarian, 1998, p. 46). Room types surrounding Ivan were defined based on the number of openings and their diverse functions dur- ing the summer and winter (Memarian \& Sadoughi, 2011; Rapoport, 2007). Seh-dari (three-door room) functioned as bedrooms, in the evening as the guest room or working room. Panj-dari (five-door room) generally served as the guest room. Talar or central room usually with sashwindowed calling orsi, acting as living places for family or religious meetings (Pirnia, 1991, p. 166). The bathroom and kitchen are also located surrounding the courtyard. Similar to Morocco's courtyard houses (Nijst, 1973 cited Rapoport, 2007), different seasonal (summer and winter) and daily movement occurred in various types of rooms.

As shown in Figure 1, the Qavam house dating back to the Qajar era (1785 to 1925), is the multiple-courtyards houses in Shiraz. Aside from Andaruni and Biruni domains, there is a third small courtyard which serves as staff quarters. There is a large talar placing at the centre of the north side of Biruni (Figure 2). This room lies adjacent to two sash-windowed rooms that was used as a reception area during the winter in addition to summer evenings (Memarian, 1998, p. 194). In each part of the north and south sides of the courtyard, there are two seh-dari (threedoor room). Parallel to the spatial arrangement of Biruni, Andaruni domain, is the Zinat al-Molk house, consisting of common rooms. However, unlike Biruni, these rooms are located on the east-west axis of the courtyard. Figure 3 depicts a large central room located at the centre of the west side and the summer places (e.g. talar and seh-dari) placed on the eastern part of Andaruni (Memarian, 1998).

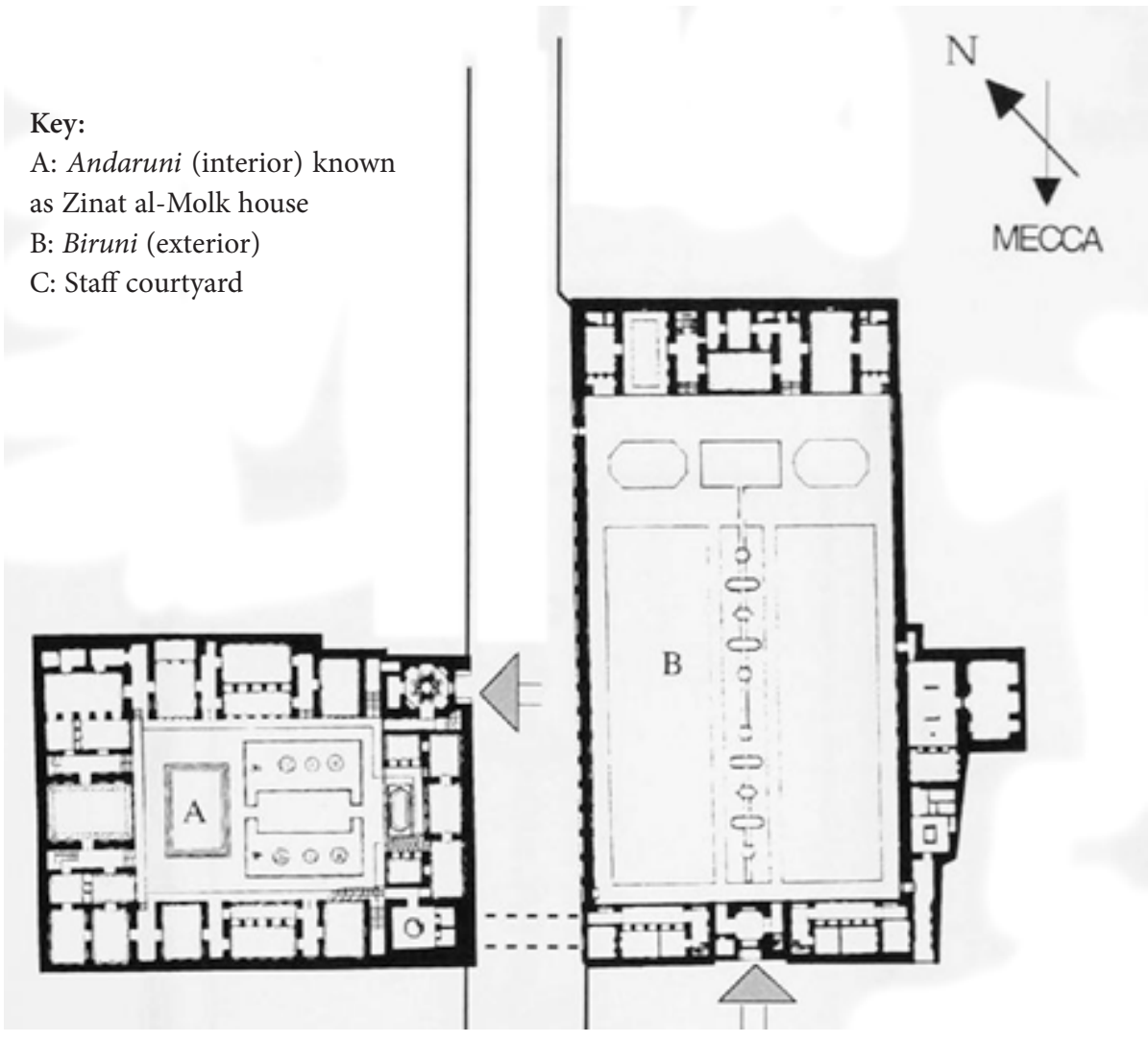

Figure 1. Private and public - plan of Qavam house in Shiraz (source: adopted from Memarian, 1998) 

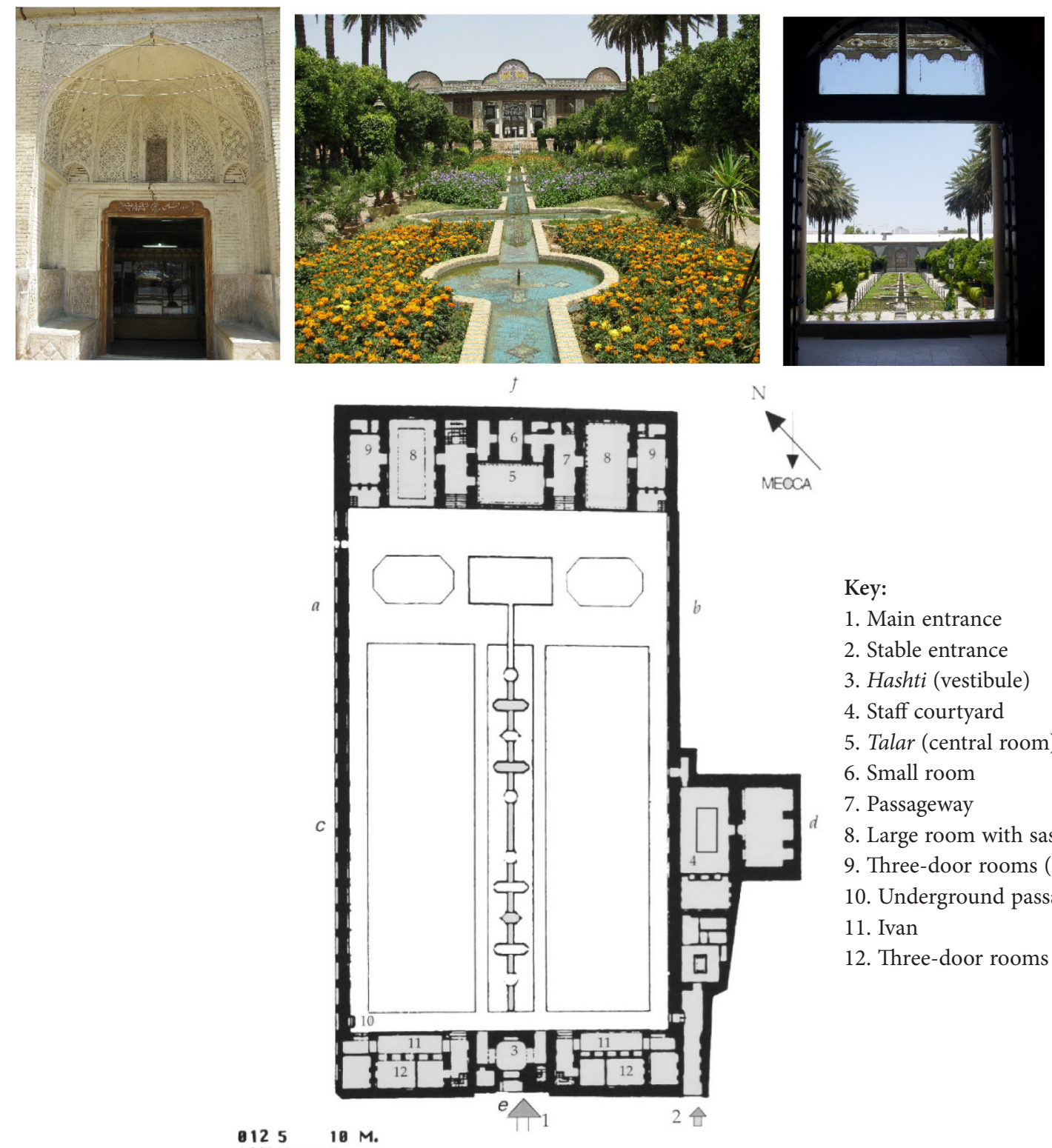

Key:

1. Main entrance

2. Stable entrance

3. Hashti (vestibule)

4. Staff courtyard

5. Talar (central room)

6. Small room

7. Passageway

8. Large room with sash-windows

9. Three-door rooms (seh-dari)

10. Underground passageway

11. Ivan

12. Three-door rooms (seh-dari)
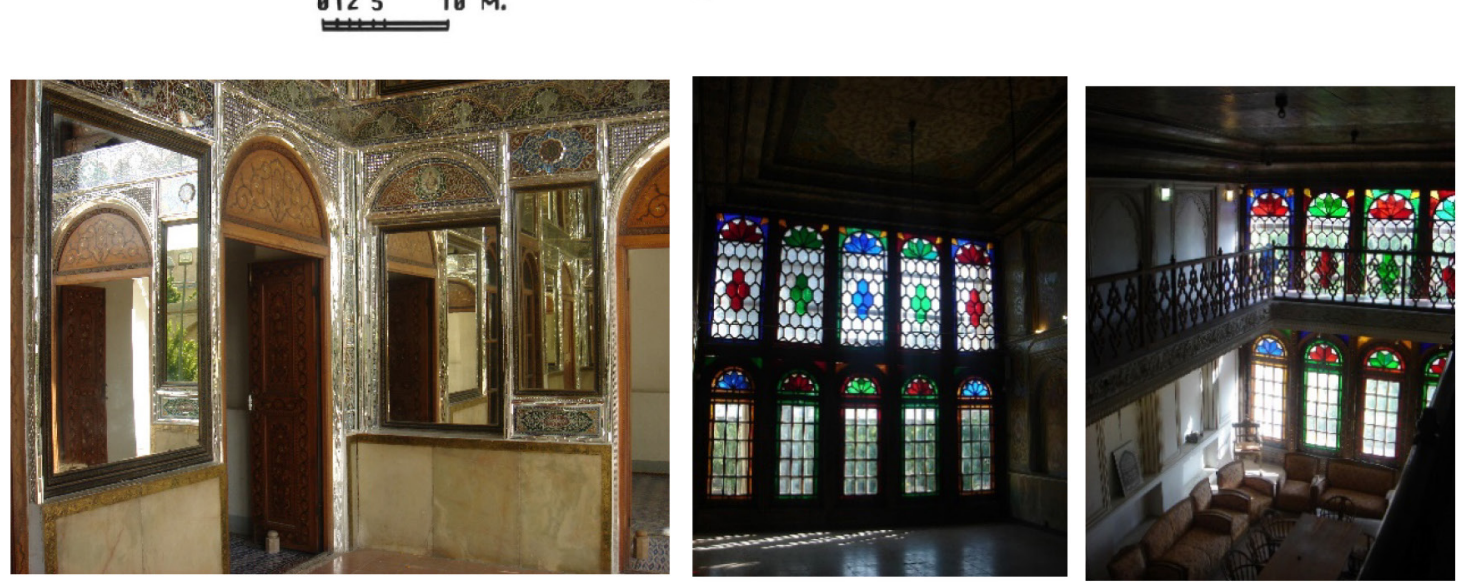

Figure 2. Ground floor plan of public domain of Qavam house (source: adopted from Memarian, 1998; source of photos Sara Mahdizadeh, summer 2014) 


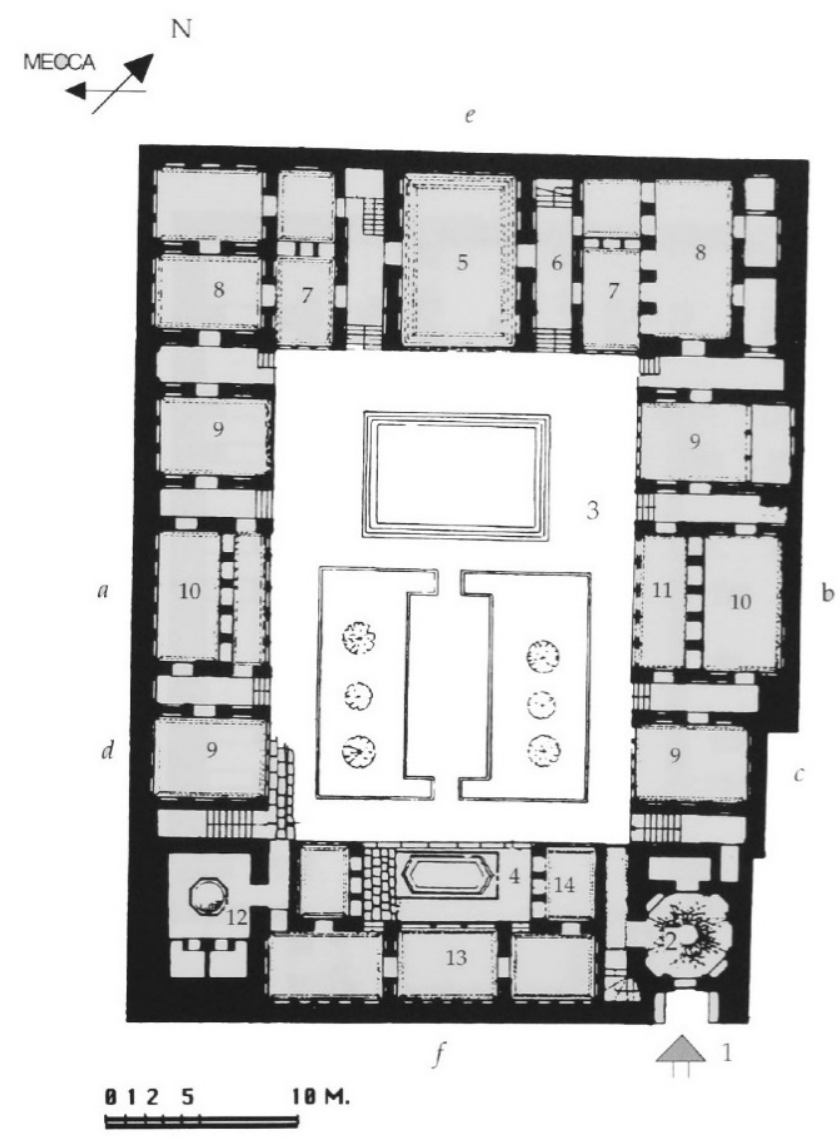

Key:

1. Main entrance

2. Vestibule (Hashti)

3. Large courtyard of Andaruni

4. Small courtyard

5. Central room

6. Passageway

7. Small sash-windowed rooms

8. Winter rooms

9. Small sash-windowed rooms

10. Five-door rooms (panj-dari)

11. Ivan

12. Small courtyard

13. Talar

14. Small three-door room (seh-dari)

Figure 3. Ground floor plan of Andaruni (private domain) of Qavam house, known as Zinat al-Molk house (source: adopted from Memarian, 1998)
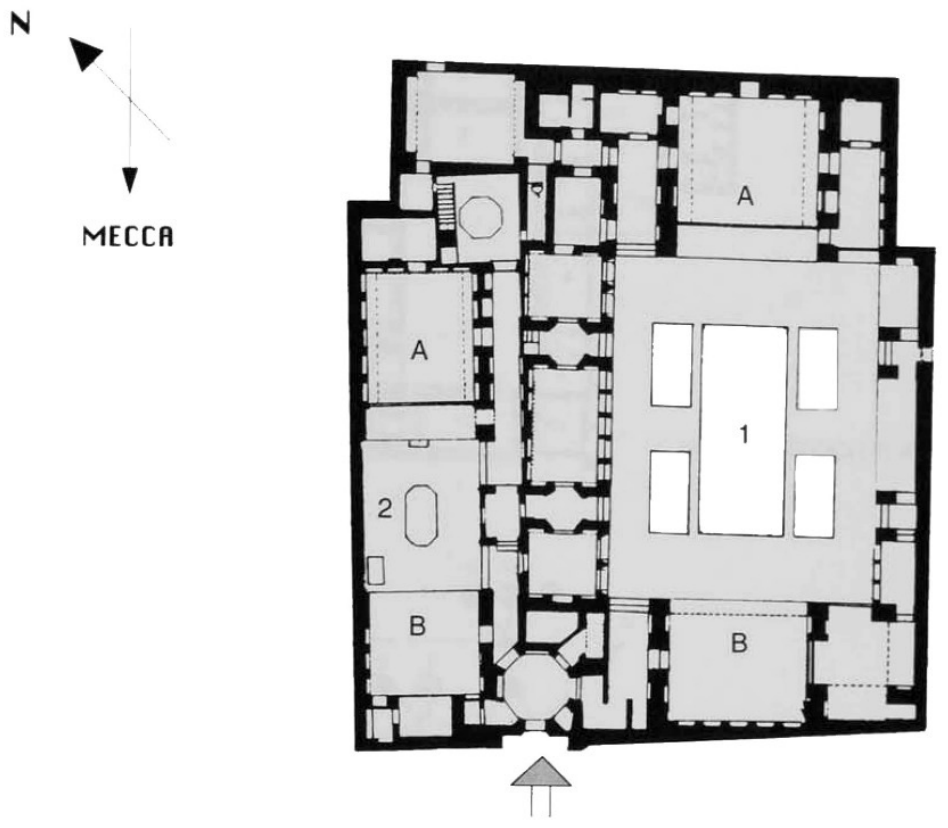

Key:

1. Andaruni (private domain)

2. Biruni (public domain)

A: Winter rooms

B: Summer rooms

Figure 4. Ground floor plan of Rasoolian courtyard house, Yazd, Iran; Not to scale (source: adopted from Memarian, 1998, p. 516) 
Climatic factors plays a significant role in changing of spatial arrangement, structure (e.g. double-shell vaults or domes), altering the role of the courtyard, and also the orientation of courtyard houses (Eskandari, 2011; Memarian \& Brown, 2006). For example, in Yazd, a city located in the hot-arid zone, apart from the components mentioned above, wind-catchers (badghir) used for ventilation, are found in most of the houses. Moreover, Yazd's houses are generally orientated towards the north-east to south-west axis. As seen in Figure 4, in the Rasoolian house, the winter spaces are located on the North-eastern and Northwestern sides of the courtyard. The summer areas include a large veranda (talar) placed on the south side (Memarian \& Sadoughi, 2011, p. 53).

From the mid-19th century onwards, Iranian urban and architectural history was integrated with modernisation, and western-influenced urbanization (Mehan, 2017b, p. 210). This gradual process of the modernization in Iran started during the Qajar dynasty (1789-1925) when the kings began to travel to Europe and import European patterns of city planning and mixed with the traditional layout of the cities; and thus became more rapid and autocratic during the Pahlavi dynasty (1925-1979) (Mehan, 2017a, p. 419). Similar to other parts of the world such as Mexico, with the rise of the "Modern Movement" (Rapoport, 2007), Iranian houses became more open, resembling outward-facing U.S suburban housing for core families with 4-5 members. As a result, the terminologies associated with courtyard houses - namely $\mathrm{Ab}$ anbar (water reservoirs), Howz (water-tank), Hashti (vestibule), Andaruni, Biruni, Sofre khane (dining room) - declined into neglect. Bani-Masoud (2009) argued that there are no longer architectural elements in contemporary houses; rather they have been turned into more construction elements without character. Materials and façades became symbols of identity; structure was an integral part of security. Electrical and mechanical services were included to boost the comfort of spaces.

\section{Methodology and findings}

The research adopted a qualitative research methodology and employed participatory narrative workshops involving in-depth interviews, photo elicitation and sketching for data collection. The multi-methods approach enabled to capture the rich narrative of participants' experiential understanding and perceptions of their houses. The criteria for selection of workshop participants were an acceptable level of education, knowledge about the lifestyle, willingness to collaborate, familiarity with modern life, and belonging to the middle-income social group. Participants had the freedom to explain their answers to open-ended questions using their terms and were not restricted to predetermined answers. Such an approach could enable the effective engagement with participants and develop more interesting narratives on topics for discussion. The workshops were for five different participants, but preparation of questions, initial discussions, interviews and conclu- sions took place during consultation meetings, of which there were more than 15. In examining the issue of growing conflict between residents' sociocultural and spatial practices and housing design in contemporary Iran, each workshop was conducted in four parts as follows:

a) Discussion of the various houses each participant had lived in;

b) Discussion of participant's everyday activities, practices and preferences;

c) Discussion of the perceptions and relevance of traditional Iranian and contemporary architecture and;

d) Co-creation process for participant's desirable house design.

The main aim of the workshop was to identify the primary features or aspects of design that residents felt were missing from where they lived. Should these feature or aspects be implemented, they would feel more content and connected to their memories and cultural/social preferences. These narratives presented the diverse and overlapping viewpoints of the participants from the four sessions of the workshop. The rich and complex narratives were then analysed to examine the relationship between various spatial arrangements and residents' sociocultural and religious practices. The research findings highlighted the a deep relationship between residents, the places in which they live and the organisation of their home; suggesting three key socio-spatial factors discussed below - social interaction, inside-outside connectedness, and privacy that influence and/define their everyday life and experiences.

\subsection{Social interaction}

Participants acknowledged the importance of social interaction in daily life. One of the participants $\mathrm{H}$ explained that "I think my most vivid memory goes back to when we were interacting with our neighbours. It was creating a feeling that, we are connected, like a family, and we can support each other." In the past, the number of people at formal and informal gatherings were large. More recently however, people tend to meet up in smaller groups. Participant $S$ talked about the changed temporalities of everyday life and relations stating, "it feels like we had more free time in the past. We often spent the evening together. It was common that children and adults played together, perhaps in courtyards. Although back then, there were not sophisticated games as there are these days, children had a better time, at least that is what I think. Nowadays they go to their room and hardly come out to interact with guests, e.g. the rest of the family, such as aunts and uncles. It is not easy to even have them at the table during meal times". Participants S, M and SH, described how they gathered together in their houses' courtyards with their extended families to have an evening snack together, something that is no longer common.

The changing lifestyle and priorities of people are reflected in the nature of the physical settings in which the social interaction takes place. Participant SH explained: "these days, people do not want to bother themselves any 
more. We used to have a large number of guests, but it required much preparation, nowadays it seems very difficult, perhaps people are lazier!".

Until the 1960s, it was not unusual for several families to live together in a big house. As explained by participant $M$, having more space and helping each other made it easier to invite guests more often. In the past, courtyards were an essential place for social interactions, but this is no longer the case. Participants S, M and SH mentioned that "we used to gather for a snack in the afternoon with our extended families in the courtyard. It rarely happens these days, perhaps because there are no courtyards anymore." The courtyard's form and scale have been changed over recent decades. Mrs M said, "I think serving guests was easier in the past. I remember we, along with other people, would go to my grandma's house in the afternoon to spend some time together. You know, people would occasionally bring some food as well, e.g. simple snacks like lettuce that they ate with a local sweet syrup. Sometimes we had quite a lot of different snacks to share with each other in the courtyard." In the past, with a prevalence of large families, it was important to have large living rooms and reception areas to accommodate occasions of hosting large numbers of guests. It was also the spaces in which family members spent most of their time when at home. Additionally, this grandness of the space and interiors reflected the financial status of residents.

It is worth noting that, a dedicated space that facilitated social events previously has been neglected in contemporary domestic architecture. The role of such spaces in delivering the social values and performances that form social interactions between extended family members and friends implores acknowledgement and reconsideration in the design process. Participants narratives on their sociospatial relationships and practices in-house demonstrates the notion of social interactions has been redefined by the emerging trends of smaller nuclear families, use of communication technologies, the increased importance of independence and privacy, and the cost and the financial aspect of spending on social events (inviting many guests).

\subsection{Inside-outside connectedness}

In traditional houses, courtyards and roof terraces provided the inside-outside connectedness alongside taking care of the need for privacy of the residents. Courtyards were multifunctional - a space for formal and informal interaction offering a comfortable microclimate and green space, that played an important part in organising the different parts of the house and connecting different spaces to each other. The significance of courtyards in Iranian culture is well depicted and documented. The film Mother (Madar) by Ali Hatami in 1989, tells the story of the way in which a mother wishes to spend her last days in her old house, with her children, who are grown up and have settled in different parts of town and outside the country. The film depicts the singular commonality amongst them being the good memories they have from their childhood which is focused on the time spent together in the courtyard, with afternoon snacks beside the pool on hot summer afternoons. In recent years, apartment buildings became a significant part of new housing typologies, and courtyards spaces disappeared thereby changing the practices linked to inside-outside interface in houses.

During the workshop, the participants' narratives about the best memories of their old houses were linked to the green and open spaces. Participants expressed their concern that such spaces which appropriately connected them to the outside have often been neglected in contemporary spatial design and planning. Participant A insisted that "I think every house needs to have such a space (courtyard), it creates a friendly atmosphere for chit-chatting."

Technology has changed lifestyles and the usage of spaces, for instance, people do not appear to need separate spaces for winter and summer as they did in the past. In contemporary housing typology, the inside/outside relationship is provided primarily through balconies which is often in conflict with the socio-cultural needs particularly the privacy for women. Interestingly, one of the female participant $S$ desired outward-looking balconies, but when the matter of privacy was discussed, she said that as a woman it is often not easy for her to use that kind of balcony, highlighting how some strong social rules still predominates and how the available spaces are used to connect with the outside.

Participants talked about the roof as a pleasant space where they used to spend time but not anymore. Participant A indicated that "although my flat's balcony is quite small and is not convenient to sleep, I still prefer to sleep there during summer nights." The preferred relationship between inside and outside for the residents is shaped by factors such as the functions of space, aesthetics and visual attraction, and comfort. Functions such as providing a place to sleep outside, are very rare and often not feasible due to a lack of space.

\subsection{Privacy}

In all traditional Iranian houses, the notion of privacy as a need, manifested spatially at the entrance and different parts of the house were designed in such a way, that it would not be physically or visually accessible' without the host's knowledge. Houses had andarooni (space specifically for the family), and birooni (spaces for strangers), this type of separation no longer exists. Participants A, $\mathrm{SH}$ and $\mathrm{M}$, liked the traditional entrance configuration as they believed it was excellent with regard to controlling visibility. All participants expressed their concerned about the higher degree of visibility that a contemporary house offered, which might allow "others" to judge one's status. e.g. furniture quality and arrangement that may reveal residents' lifestyle and their financial status. $M$ explained that "when the entrance door of our courtyard is open people can see inside from the street. To me this is like a disaster." $\mathrm{SH}$ said, "in the past, the walls surrounding our courtyard were lower until I noticed someone was watching inside 
the courtyard while we were there. So, I raised the height of the wall to prevent that."

Interestingly, there are places where the notions of privacy seem to have been reconceptualised due to technological interventions in urban living. Participant $S$ said, "I used to put images of the family in the living area and remove them when hosting some specific guests, but not anymore." The reason for this is mainly due to the prevalence of social media platforms where people share their more personal information. Hence sharing such information to outsiders is no longer considered taboo anymore.

Participant A described his granddad's house as a nice and memorable place until one of the neighbours built a tall building in front of it: "Because the residents in the new building were able to see inside the courtyard, it was not pleasant to use it as often as before." As mentioned earlier, culturally, the preference is to live in houses that provide adequate privacy. Unlike the apartment buildings, houses with the provision of courtyards, spaces were no longer active spaces due to the changing urban fabric of the contemporary city. Privacy was also more of a concern for participants who were engaged in activities that were not culturally/religiously accepted, such as drinking alcoholic beverages for this made them vulnerable to societal judgment and prejudice. Whist participants' narratives exhibit a need for privacy that was diverse in range and degree, privacy is mostly defined by the controlled/filtered access to the outside. This provides them with the control over revealing socio-cultural practices and personal choices to others.

Throughout the Middle East, current rapid changes in the economic and social conditions have led to the disruption of continuity of historical tradition in the region's urban form (Kiet, 2011, p. 36). Likewise, with modernisation and changing lifestyles, many social and cultural values have been gradually fading or re-interpreted in Iranian society. There is increasing concern about the result of rapid modernisation processes and the dramatic break with traditional concepts of design in Iran that introduced a new layout which did not completely satisfy the new requirement for of newer ways of living for the majority of people in Iran (Mirmoghtadaee, 2009, p. 70).

Johnson (1993, p. 28) has studied housing culture to determine its meaning and relation (or expression) to cultural values, in order to fully understand them. Johnson suggests that according to recent developments, meaning is not a single or unique one, it is changeable for different reasons (Johnson, 1993, p. 30). Similarly, Hanson clarifies: "Houses are not just assemblages of individual rooms but intricate patterns of organized space, governed by rules and conventions on the size and configuration of rooms, which domestic activities go together, how the interior should be decorated and furnished and what kinds of household objects are appropriate in each setting, how family members relate to one another in different spaces, and how and where guests should be received and entertained in the home" (Hanson, 2003, p. 324). Historically, privacy was of utmost concern, and the house was considered a sacred space. Nowadays the notion and percep- tion of privacy has changed. Unlike the past, women are more involved in society and social activities; often the home is not a place they spend most of their time, and this is further reflected in spatial design and considerations. For instance, current designs do not emphasise the importance of traditional reception areas, and in many cases, the same spaces are used for public (non-private) and private living, a feature that might be attributed to fewer social interactions, such as family gatherings and the reduced presence of extended families. The early 20thcentury separation between male and female guests is no longer a requirement.

Nonetheless, religion still plays an active role in Iranian society. Unlike Western countries, the government directly interferes in religious issues and reinforces them; Islamic guidelines need to be clearly respected in society. Whilst people in their own homes might not consider such religious rules relevant, the preference is for such behaviour to remain hidden from view. In some cases, this could be attributed to government-enforced regulations and the consequences of publicly violating them, rather than residents' preferences. With regards to the latter, privacy is a prime example, and it still has an important role to play in Iran's cultural context. Nevertheless, this has been overlooked in designing new houses. There have been some attempts to add some especially visually appealing features that resonate or replace some aspects of Iranian traditional houses, such as a balcony as replacement for a courtyard. It is regrettable that in many cases, functionality of such space has been neglected, for example a fully exposed balcony in an apartment which could rarely be used by female members of the family (if they don't want to contravene Islamic regulations).

\section{Discussion: spatiality as a socio-cultural paradigm}

Focusing on the implications of the three propositions presented in the pilot study based on the participants' narratives, there is still a major gap between people's needs, practices and spatial organisation of housing in Iran. The analysis of the pilot study propositions further highlights various neglected socio-spatial aspects relevant to residents' needs. This presents opportunities for re-interpreting traditional architectural elements in Iran for the contemporary living. Design propositions developed based on participants' narratives, emphasised the emerging social and cultural needs and practices of people, showing the complex relationship between residents, the places in which they live, and its spatial planning and organisation. This complex relationship embeds critical insights on changing everyday practices, spatial relationships and perceptions of people. To delineate these complicated, interconnected and multidimensional relationships, we argue spatial relations needs to be reintroduced in the socio-cultural discourses to provide acritical lens for examining the socio-cultural processes, urban changes and transformations in the contemporary milieu. 
Some of the leading proponents of the spatial theory are Lefebvre, Foucault, de Certeau, Simmel and postmodern geographers such as Soja, Harvey and Massey. All have explained through their work, the ways in which interrelated dynamics of society and space is creating a paradigm shift in understanding any phenomena. This spatial turn in urban studies instigated by Lefebvre's Production of space, has helped in unravelling space as a fundamental force that shapes society and also a "reflective mirror of societal modernization" (Soja, 1996).

Complex urbanity in cities is caused by several factors which are social, cultural, technical, political, and physical. All these factors are multi-dimensional and are interrelated. Within this labyrinth lies the diverse processes that influence or define the socio-cultural transformations and perceptions of people. These processes relate, and occur at different levels - individual, community, national, regional and global. The processes at individual and community level tend to be far more significant and powerful in mooting societal transformations and change. Within any discipline-specific examination relating to people and society, it is important to acknowledge that all socio-cultural processes are ultimately linked to those whose very existence is spatial. It will not be an exaggeration to note here that understanding spatial relations is critical for understanding society. Spatiality "combines all conditions and practices of individual and social life that are linked to the relative position of individuals and groups with regard to one another" (Pumain, 2004).

Physical forms and spaces emerge as a result of complex interaction between people and diverse factors (social, economic, cultural, political and environmental) (Tonkiss, 2013). These physicalities are manifestations of peoples' need, concerns, aspirations, conflicts, negotiations and appropriations of and/with the diverse factors. There have been seminal works by scholars bridging the spatial and non-spatial in Sociology (Simmel), human geography (Relph, Tuan), anthropology, architectural and urban theory (Rapoport, Low), that signify the relationship between people and spatial relationships.

Proponents have highlighted and criticised the epistemological impasse that arises due to the vested research interest which distances the built environment from people and the social processes and experience in cities (Griffiths \& von Lünen, 2016). In a recent highly interdisciplinary work, "The Social Fabric of Cities", Netto (2017) showcases the significance of the relationship between social processes and spatiality of cities. A key point Netto's work brings to light, is that even if spatial factors are only implicit in people's spatial choices and decisions, it would lead to bigger social challenges in cities. He gives several examples of how choices of urban actors with different intent lead to segregated societies. To illustrate, whilst the reason for an individual's choice to be in a gated development might be safety and comfort, it unintentionally creates segregation in cities.

Examining cultural processes essentially involve understanding behavioural patterns (Kroeber \& Kluckhohn,
1952, p. 181) formed as a result of negotiations of ideas, values and beliefs of society over time. The result of this negotiation processes is spatially and symbolically articulated in the physical environment to create new cultural forms and meanings. The patterns which are at a superficial level, often viewed as "a loose network of imperfectly shared knowledge representations for coordinating social transactions" (Leung et al., 2011) are instead formed by a gradual, careful and constant processes of negotiation, adaptation and transmission, principally embedded in space and time. We can say that the spatio-temporal practices and dynamics configures the situatedness of cultural processes in the milieu.

\section{Conclusions}

The everyday spatial practices act as a matrix for developing, restructuring and defining peoples' perception of social-cultural values, which manifest through their spatial relations and choices. Using a pilot casestudy in Kerman, the paper examined how the everyday spatial practices and experiences are closely linked to the socio-cultural meanings and connotations both in traditional and contemporary context. The paper argues that spatial relations and practices offer an interesting lens to examine the socio-cultural processes and urban transformations in cities.

\section{Funding}

The research was not supported by any external funding.

\section{Author contributions}

Molki, designed the research and anlaysed the data; Mahadizadeh and Mehan contributed to data analysis and writing Rajendran analyzed the data and wrote the paper. All authors have read and agreed to the published version of the manuscript.

\section{Disclosure statement}

All authors declare there are no competing financial, professional, or personal interests from other parties.

\section{References}

Altman, I. (1992). A transactional perspective on transitions to new environments. Environment and Behavior, 24(2), 268280. https://doi.org/10.1177/0013916592242008

Bachelard, G. (2014). The poetics of space. Penguin Books.

Bani-Masoud, A. (2020). Contemporary architecture in Iran: from 1925 to the present. Independently Published.

Birdwell-Pheasant, D., \& Lawrence-Züniga, D. (1999). House life: space, place and family in Europe. Routledge.

Casey, E. (1998). The fate of place: A philosophical history (new ed.). University of California Press.

Cuthberted, A. R. (2003). Designing cities: critical readings in urban design. Blackwell Publishers Ltd. 
Dehkhoda, A. A. (Ed.). (1940). Loghatname Dehkhoda [Dehkhoda dictionary]. College of Science and Literature, University of Tehran Publishing.

Eskandari, P. (2011). Analysis of traditional Iranian houses of Kashan, Iran in terms of space organization and access design. Eastern Mediterranean University (EMU).

Gifford, R. (2014). Environmental psychology matters. Annual Review of Psychology, 65, 541-579. https://doi.org/10.1146/annurev-psych-010213-115048

Griffiths, S., \& von Lünen, A. (2016). Spatial cultures: towards a new social morphology of cities past and present. Routledge. https://doi.org/10.4324/9781315610269

Hanson, J. (2003). Decoding homes and houses. Cambridge University Press.

Heidegger, M. (2001). Poetry, language, thought (A. Hofstadter, Trans.). Harper \& Row. (Original work published 1971)

Johnson, M. H. (1993). Housing culture: traditional architecture in an English landscape. UCL Press, Routledge.

Kiet, A. (2011). Arab culture and urban form. Focus, 8(1), 10. https://doi.org/10.15368/focus.2011v8n1.4

Kroeber, A. L., \& Kluckhohn, C. (1952). Culture a critical review of concepts and definitions. In Papers of the Peabody Museum of American Archaeology and Ethnology, Harvard University (Vol. 47, No. 1, pp. 3-217). The Museum.

Lane, B. M. (2006). Housing and dwelling: perspectives on modern domestic architecture. Routledge.

Leung, A. K.-y., Chiu, C.-y., \& Hong, Y.-y. (2011). Cultural processes: A social psychological perspective. Cambridge University Press. https://doi.org/10.1017/CBO9780511779374

Malpas, J. (2012). Putting space in place: philosophical topography and relational geography. Environment and Planning D: Society and Space, 30(2), 226-242. https://doi.org/10.1068/d20810

Marcus, C. C. (2006). House as a mirror of self: Exploring the deeper meaning of home. Nicolas-Hays, Inc.

Mehan, A. (2017a). Manifestation of modernity in Iranian public squares: Baharestan square (1826-1978). International Journal of Heritage Architecture, 1(3), 411-420. https://doi.org/10.2495/HA-V1-N3-411-420

Mehan, A. (2017b). "Tabula Rasa" planning: creative destruction and building a new urban identity in Tehran. Journal of Architecture and Urbanism, 41(3), 210-220.

https://doi.org/10.3846/20297955.2017.1355277
Memarian, G. H. (1998). House typology in Iran (with special reference to Shiraz) [PhD thesis]. The University of Manchester.

Memarian, G. H., \& Brown, F. (2006). The shared characteristics of Iranian and Arab courtyard houses. In B. Edwards, M. Sibley, M. Hakmi, \& P. Land (Eds.), Courtyard housing: past, present and future (pp. 21-30). Taylor \& Francis.

Memarian, G. H., \& Sadoughi, A. (2011). Application of access graphs and home culture: examining factors relative to climate and privacy in Iranian houses. Scientific Research and Essays, 6(30), 6350-6363. https://doi.org/10.5897/SRE11.1620

Miller, D. (2001). Home possessions: material culture behind closed doors. Berg.

Mirmoghtadaee, M. (2009). Process of housing transformation in Iran. Journal of Construction in Developing Countries, 14(1), 69-80.

Netto, V. M. (2017). 'The social fabric of cities': a tripartite approach to cities as systems of interaction. Area Development and Policy, 2(2), 130-153. https://doi.org/10.1080/23792949.2017.1315540

Nijst, A. (1973). Living on the edge of the Sahara: a study of traditional forms of habitation and types of settlement in Morocco. Government Publishing Office.

Norberg-Schulz, C. (1979). Genius Loci: towards a phenomenology of architecture. Rizzoli.

Norberg-Schulz, C. (1980). Genius Loci: towards a phenomenology of architecture. Rizzoli.

Pirnia, M. K. (1991). Introduction to Iranian Islamic architecture Tehran. Iran University of Science and Technology.

Proshansky, H. M., Ittelson, W. H., \& Rivlin, L. G. (1970a). Environmental psychology: Man and his physical setting. Holt, Rinehart and Winston.

Proshansky, H. M., Ittelson, W. H., \& Rivlin, L. G. (1970b). The influence of the physical environment on behavior: some basic assumptions. In Environmental psychology: man and his physical setting (pp. 27-36). Holt, Rinehart and Winston.

Pumain, D. (2004). Spatiality. Retrieved 29 August, 2018, from http://www.hypergeo.eu/spip.php?article181\#

Rapoport, A. (2007). The nature of the courtyard house: a conceptual analysis. Traditional Dwellings and Settlements Review, 18(2), 57-72.

Soja, E. W. (1996). Thirdspace: journeys to Los Angeles and other real-and-imagined places (1st ed.). Wiley-Blackwell.

Tonkiss, F. (2013). Cities by design: the social life of urban form. Polity. 